\title{
Evaluation of Chlorpyrifos Tolerance and Degradation by Non-Toxigenic Aspergillus Section Flavi Strains Isolated from Agricultural Soils
}

\section{Cecilia Soledad Carranza ${ }^{1,3}$, Melisa Eglé Aluffi ${ }^{1,3}$, Carla Lorena Barberis ${ }^{1,2}$ and Carina Elizabeth Magnoli ${ }^{1,2}$}

\author{
${ }^{1}$ Departamento de Microbiología e Inmunología, Facultad de Ciencias Exactas, Físico, \\ Químicas y Naturales, Universidad Nacional de Río Cuarto, Ruta Nacional Nº 36 Km 601 (5800) \\ Río Cuarto, Córdoba, Argentina \\ ${ }^{2}$ Member of the Research Career of CONICET, Argentina \\ ${ }^{3}$ Fellowship of CONICET, Argentina \\ *Corresponding author
}

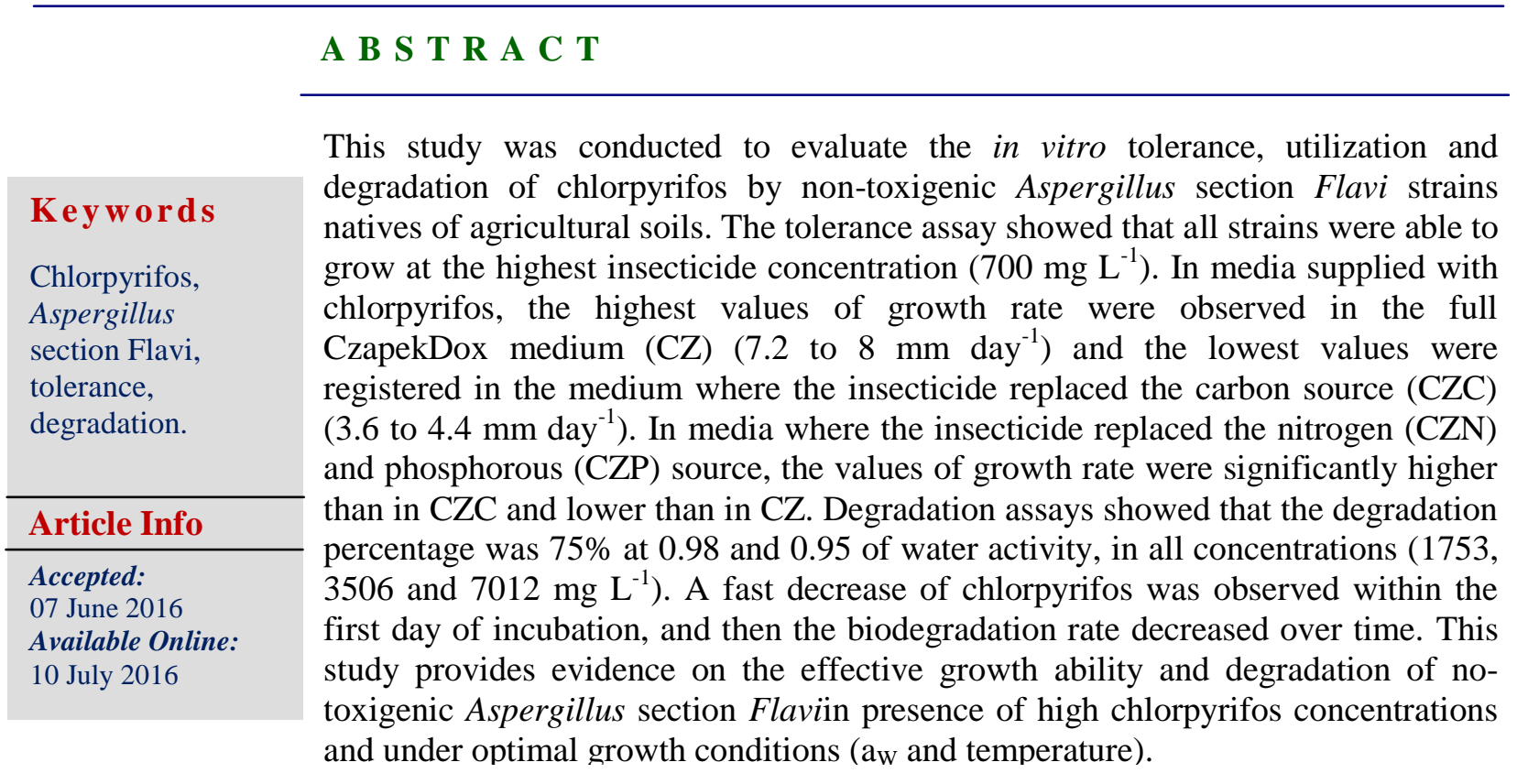

\section{Introduction}

Pesticides are one of the most important substances to which man is exposed. Argentina's economy is traditionally based on agricultural production; this brings the implementation of significant quantities of pesticides that impact on health and environmental quality. Since the 70', data about the environmental impact, food and human health is informed (Brunstein et al., 2009). An important change in the last years was the introduction of glyphosate-resistant transgenic soybean, which led to a significant increase in crop yields and in sowed area. These increases caused an important growth in the use of technological packages based on the utilization of 
genetically modified seeds and pesticides like glyphosate, chlorpyrifos and pyrethroids (VillamilLepori et al., 2013). According to the Chamber of Agricultural Health and Fertilizer (CASAFE, 2014), in the last twenty two years in Argentina the utilization of pesticides increased in $858 \%$ while the cereals and oilseeds cultivated area and crop yields had only an increase of 50 and 30\%; respectively. The chlorpyrifos doses applied depend on the crop, the insect and the commercial formulation. For soybean and maize, the doses range between 0.40 and $1.60 \mathrm{~L} \mathrm{ha}^{-1}$ and between 1.2 and $4 \mathrm{~L} \mathrm{ha}^{-1}$, respectively (Agrobit, 2013). Pesticide use is questioned, mainly in developed countries, due to potential accumulation of residues and degradation products, and negative effects on soil microorganisms. Toxicological risks on animals, humans and environment are being increasingly studied (Antunes et al., 2010; Alvarez et al., 2013).

Chlorpyrifos (O,O-diethyl-O-3,5,6-trichloro2 pyridyl phosphorothioate) is an organophosphate insecticide for foliar or soil application. It was commonly used for both household and agricultural applications until it was banned for household use by the USEPA in 2000 (EPA, 2000). This insecticide is one of the most detected in surface and ground water in the world (Gilliom et al., 2000; Domagalski and Munday, 2003) and in water and soil in Argentina (Loewy et al., 2011). Their solubility in water is limited and it can be adsorbed to suspended particles and sediments. The half-life of this insecticide in soil has been estimated at around 360 days (EPA, 2000). Temperature, $\mathrm{pH}$, moisture, organic carbon content and pesticide formulation can produce variations in the half-life in soil (Alvarez et al., 2013).

Chlorpyrifos degradation on soil is influenced by environmental factors like $\mathrm{pH}$, moisture and temperature; likewise the commercial formulation and application rates. Biotic and abiotic process contributes to the degradation. A key process is the enzymatic hydrolysis, in which the rate increases with $\mathrm{pH}$ and temperature; another important process is the photolytic degradation (Gebremariam et al., 2012). Nevertheless, the main pathway of degradation seems to be aerobic and anaerobic metabolism (Awad et al., 2011; Massiha et al., 2011). Depending on the microorganisms and environmental conditions, chlorpyrifoscleavage produce two major metabolites: 3,5,6-trichloro-2pyridinol (TCP) and dieth-ylthiophosphoric acid (DETP), while some other metabolites, are produced in very minute quantities (Bootharaju and Pradeep, 2012).

Several studies have demonstrated that the inoculation of adapted microorganisms on pesticide-contaminated soils is a good option to decontaminate them (Diez, 2010; Abo-Amer, 2011; Massiha et al., 2011). There are a great diversity of microorganisms producers of organophosphates degrading enzymes in chlorpyrifos-exposed soils (Bhagobaty and Malik, 2008; Sasikala et al., 2012). Several microbial species capable to metabolize chlorpyrifos as sole source of carbon have been isolated from pesticide contaminated soils, sludge or waste water by enrichment culture techniques (Ghanem et al., 2007; Latifi et al., 2012; Liu et al., 2012; Savitha and Raman, 2012). Most investigations have focused mainly in bacteria; few of them have demonstrated that chlorpyrifos could be degraded by fungi (Yu et al., 2006; Chu et al., 2008; Fang et al., 2008).Filamentous fungi are part of the soil microbiota and they have evolved for use more efficiently several solid substrates, growing on their surface and penetrating in their matrices. These microorganisms are capable to produce and secrete enzymes that turn 
complex macromolecules to simple compounds for their growth and metabolism (Rabinovich et al., 2004).

Aspergillus sp. is one of the most prevalent genera isolated from Argentinean agricultural soils (Carranza et al., 2014; 2016a). Being Aspergillus section Flavi strains isolated in major frequency. The in vitro glyphosate tolerance was evaluated. All strains tested were able to develop at the highest concentration assayed (500 mM) regardless the water availability condition (Carranza et al., 2016a). In addition, Aspergillus section Nigri strains also isolated from these soils, resulted tolerant to chlorpyrifos (Carranza et al., 2014). However, there is no information about chlorpyrifos tolerance or degradation by Aspergillus section Flavi strains isolated from these soils. Therefore, the aim of the present study was to evaluate the in vitro tolerance, utilization and degradation of chlorpyrifos by non-toxigenic Aspergillus section Flavi strains natives of agricultural soils.

\section{Materials and Methods}

\section{Fungal strains}

Three A.oryzae strains (AM 1, AM 2 and GM 3) and one A.flavus (GM 4) previously identified by molecular methods were used (Carranza et al., 2016a).These strains were previously isolated from fields destined to maize and soybean production(Carranza et al., 2014). These fields have been exposed to successive applications of pesticides during the last decade. The ability of the strains tested to produce aflatoxins and cyclopiazonic acid was evaluated previously (Barberis et al., 2012; Carranza et al., 2014); and they resulted non-toxigenics. The strains belong to our culture collection at the Department of Microbiology and
Immunology, in the National University of Río Cuarto, Córdoba, Argentina, and they are maintained in $15 \%$ of glycerol (SigmaAldrich, St. Louis, MO, USA) at $-80^{\circ} \mathrm{C}$.

The nucleotide sequences for the calmodulin and $\beta$ - tubulin gene were deposited in GenBank under accession numbers KX298157- KX306816, KX298158KX306817, KX298159- KX306818 and KX306820- KX306819 for the strains AM1, AM2, GM3 and GM4, respectively

\section{Chlorpyrifos}

The chlorpyrifos used in this study was obtained from commercial formulation (Hor-tal®). A stock solution of $10 \mathrm{~g} \mathrm{~L}^{-1}$ of the active ingredient was prepared by dissolving the corresponding volume of the insecticide in $100 \mathrm{ml}$ of sterile distilled water $\left(\mathrm{vv}^{-1}\right)$.

For tolerance, growth and degradation experiments, the appropriate concentration of stock solution was applied to the sterilized media (tempered at $45-50^{\circ} \mathrm{C}$ ) to obtain the required final concentrations. They are higher than the chlorpyrifos application rates recommended on field (2$2.75 \mathrm{~kg} \mathrm{ha}^{-1}$ ) (Muzio et al., 2008).

\section{Chlorpyrifos tolerance by Aspergillus section Flavi strains}

For tolerance assays, the methodology used was descripted in a previous study (Carranza et al., 2016a).Soybean extract agar (SEA) was used and the water activity $\left(\mathrm{a}_{\mathrm{W}}\right)$ of the basic medium was adjusted to 0.995 and 0.980 with known amounts of glycerol (Dallyn and Fox, 1980).The media were autoclaved at $120^{\circ} \mathrm{C}$ for $20 \mathrm{~min}$. The stock solution of insecticide was applied to the sterilized media to obtain the required final concentrations $(100,200,300,400,500,600$ 
and $\left.700 \mathrm{mg} \mathrm{L} \mathrm{L}^{-1}\right)$.Homogenized media were poured into9-cm sterile petri dishes. Water activity was checked with an AquaLab Series 3 (Decagon Devices, Inc., Pullman, WA, USA). Controls plates without chlorpyrifos at each $\mathrm{a}_{\mathrm{W}}$ condition were prepared. Water activity was measured at the end of the experiment in order to detect any significant deviation.

The media were needle-inoculated centrally with a spore suspension in soft agar from 7day-old cultures on malt extract agar (MEA). Inoculated Petri dishes of the same aw were sealed inside the same polyethylene bags. Four replicate plates per treatment were used and incubated at $25^{\circ} \mathrm{C}$ for 28 days. Each analysis was carried out in quadruplicate and all of the experiments were repeated twice.

The growth measurement was done as it is detailed in the study done by Barberis et al. (2010). Two measures of colony diameter at right angles to each other were taken daily from each replicate plate. The radius of the colony was plotted against time, and a linear regression was applied in order to obtain the growth rate as the slope of the line to the $\mathrm{X}$ axis. The percentage of growth inhibition produced by chlorpyrifos was calculated in each treatment. The lag phase (h) was also determined

Growth of Aspergillus section Flavi strains in the presence of commercial chlorpyrifos formulation as sole source of carbon, phosphorus or nitrogen

For growth assays, Czapek Dox agar medium (sucrose $30 \mathrm{~g}, \mathrm{NaNO}_{3} 3 \mathrm{~g}, \mathrm{~K}_{2} \mathrm{HPO}_{4}$ $1 \mathrm{~g}, \quad \mathrm{MgSO}_{4} .7 \mathrm{H}_{2} \mathrm{O} \quad 0.25 \mathrm{~g}, \quad \mathrm{KCl} \quad 0.5 \mathrm{~g}$, $\mathrm{FeSO}_{4} .7 \mathrm{H}_{2} \mathrm{O} 0.01 \mathrm{~g}$, agar $15 \mathrm{~g}$, distilled water 1L) at $0.995 \pm 0.002$ of aw was used as basal medium. In this medium, sucrose was replaced by chlorpyrifos at a final concentration of $50 \mathrm{mg} \mathrm{L}^{-1}$ as sole carbon source. When chlorpyrifos was used as sole source of phosphorus or nitrogen, $\mathrm{K}_{2} \mathrm{HPO}_{4}$ or $\mathrm{NaNO}_{3}$ were replaced by chlorpyrifos at final concentration of $10 \mathrm{mg} \mathrm{L}^{-1}$. These concentrations were selected based on the percentages that the carbon, nitrogen or phosphorous sources should represent in the fungal media (Gao et al., 2012; Rokade and Mali, 2013). The Czapek Dox agar is referred to as $\mathrm{CZ}$. The growth medium in which chlorpyrifos replaces the organic carbon source is referred to as CZC. On the other hand, when the mineral phosphate or nitrogen sources are replaced by this insecticide the media are referred to as CZP or CZN, respectively. The water agar (WA) and $\mathrm{CZ}$ media were used as control treatments.

The inoculation, incubation and estimation of growth parameters were made as it is explained above by tolerance assays. Each analysis was carried out in quadruplicate and all of the experiments were repeated twice.

Chlorpyrifos degradation by $A$. oryzae on synthetic medium

The ability of A. oryzae (AM 1 and AM 2) to degrade different concentrations (1753, 3506 and $7012 \mathrm{mg} \mathrm{L}^{-1}$ ) of chlorpyrifos was tested. Broth Czapeck medium (CZ) adjusted to $0.98,0.95$ and 0.93 of aw with the addition of glycerol was used. Aliquots $(50 \mathrm{~mL})$ of $\mathrm{CZ}$ without insecticide were added aseptically into sterilized conical flasks and were immediately inoculated with one agar plugs $(3 \mathrm{~mm})$ taken from the margins of actively growing cultures of each strain in the appropriate agar media. Subsequently, inoculated flasks were placed in a shaking incubator $(60 \mathrm{rpm})$ at $25^{\circ} \mathrm{C}$ and the fungi were allowed to grow in the absence of the insecticide for 3 days. After this period, all flasks were supplemented 
with the different concentration of insecticide. The corresponding controls were included (flasks without chlorpyrifos, flasks with the insecticide but without strains). Immediately after insecticide addition (0) and at 1, 2, 5, 10, 15, 20 and 30 days, subsamples of each culture $(1 \mathrm{~mL})$ were removed and insecticide residual concentration was determined by HPLC. All the treatments were done by triplicate and repeated three times.

For chlorpyrifos extraction and detection, subsamples of $1 \mathrm{~mL}$ of the liquid medium, was mixed with $2 \mathrm{~mL}$ of a mixture of acetonitrile:methanol $(80: 20 \quad \mathrm{v}: \mathrm{v})$ and vortexed $(30 \mathrm{~s})$. The mixtures were subsequently passed through a $0.45 \mu \mathrm{m}$ syringe filter (Sartorius Stedim Biotech $\mathrm{GmbH}$ Goettingen Germany) and the filtrates were used for HPLC analysis followed the methodology proposed by Karas et al., (2011). The HPLC system consisted of a Hewlett-Packard 1100 pump (Palo Alto, CA, USA) connected to a Hewlett-Packard 1046 programmable fluorescence detector, interfaced to a Hewlett-Packard Chem Station. Chromatographic separations were performed on a stainless steel Supelcosil LC-ABZ C18 reversed-phase column $(150 \times 4.6 \mathrm{~mm}$ i.d., $5 \mu \mathrm{l}$ particle size; Supelco, PA, USA). Chlorpyrifos was quantified by correlating peak height of sample extracts and those of standard curves. Standard curves were constructed with different levels of Chlorpyrifos (PESTANAL $^{\circledR}$, analytical standard,45395 SIGMA-ALDRICH).This insecticide was quantified by correlating peak height of sample extracts and those of standard curves. The detection limit of the analytical method was $1 \mathrm{ng} \mathrm{g}^{-1}$ of sample. Concentration of chlorpyrifos $\left(\mathrm{mg} \mathrm{L}^{-1}\right)$ in the media was plotted against time (days) to calculate the percentage of degradation on each condition assayed.

\section{Assay of spiking and recovery of chlorpyrifos}

Each chlorpyrifos-free medium sample (50 $\mathrm{mL}$ ) contained in a $250 \mathrm{~mL}$ Erlenmeyer flask was spiked with an equivalent of 0.1 , $0.5,1.0$ and $2 \mathrm{mgL}^{-1}$ of chlorpyrifos. Spiking was carried out by triplicate and a single analysis of the blank sample was carried out. The chlorpyrifos concentration was determined, using the protocol previously described.

\section{Statistical Analysis}

Data analysis of in vitro evaluation of chlorpyrifos tolerance, replacement effect of the carbon, phosphorus or nitrogen source by chlorpyrifos and chlorpyrifos degradation levels by Aspergillus section Flavi strains were performed by analysis of variance. All data were transformed to $\log _{10}(\mathrm{x}+1)$ to obtain the homogeneity of variance. Means were compared also by Fisher's protected LSD test to determine the influence of the variables assayed $\left(\mathrm{a}_{\mathrm{W}}\right.$ and insecticide concentration) in the growth rate, lag phase and residual chlorpyrifos concentration by the strains tested. The analysis was conducted using PROC GLM in SAS (SAS Institute, Cary, NC).

\section{Results and Discussion}

\section{Chlorpyrifos tolerance by Aspergillus section Flavi strains}

Figure 1 shows the effect of different chlorpyrifos concentrations on the growth rate of four Aspergillus section Flavi strains at two aw conditions (0.995 and 0.980). Control treatments showed a significant reduction in growth rate when aw decreased only in AM 2 and GM 4 strains ( $<<0.0001)$. Regarding chlorpyrifos treatments, in general, this parameter was similar or higher 
at 0.995 than at 0.980 of aw; except in some conditions where the opposite results were observed. All the strains tested were able to grow at the highest insecticide concentration assayed $\left(700 \mathrm{mg} \mathrm{L}^{-1}\right)$. Particularly, at the two highest concentrations (600 and/or 700 $\mathrm{mg} \mathrm{L}^{-1}$ ), higher values of growth rate were observed at 0.980 than at 0.995 of $\mathrm{a}_{\mathrm{W}}$ for the strains AM 1, AM 2 and GM 4. At 0.995 of $\mathrm{a}_{\mathrm{W}}$ and the lowest chlorpyrifos concentrations (100 and $\left.200 \mathrm{mgL}^{-1}\right)$, this growth parameter remained constant. On the contrary, lower values of growth rate comparing to the control were observed at the highest insecticide concentrations assayed $(p<0.0001)$. An exception was observed in GM 3 strain where at $300 \mathrm{mg} \mathrm{L}^{-}$ 1 and 0.995 of $a_{W}$ the growth rate was significantly higher than in the control treatment. At 0.980 of $\mathrm{a}_{\mathrm{w}}$, reductions in growth rate when chlorpyrifos concentration increased were observed; except in GM 4 strain. The highest values of this parameter were observed at 100 and $200 \mathrm{mg} \mathrm{L}^{-1}$ of insecticide for this strain. Meanwhile, from 400 to $700 \mathrm{mg} \mathrm{L}^{-1}$, growth rate was similar and significantly lower than the value registered in the respective control. The reductions of growth rate observed along the experiment did not achieve a $50 \%$ reduction in comparison to control treatments.

As regard lag phase, the values registered in control treatments of all strains tested were significantly higher at 0.980 than at 0.995 of $\mathrm{a}_{\mathrm{W}}(\mathrm{p}<0.0001)$ (Table 1). In general, this behavior pattern was also observed in the chlorpyrifos treatments. As expected, significant increases in lag phases with increasing insecticide concentration were observed in all strains and $\mathrm{a}_{\mathrm{w}}$ tested. At 0.995, the duration of the lag phases of the strain GM 3 was larger than the ones of the other strains along the experiment. The most noticeable increase in this growth parameter was observed with $700 \mathrm{mg} \mathrm{L}^{-1}$ of chlorpyrifos $(78 \%)(\mathrm{p}<0.0001)$. Particularly, at 0.980 , the lag phases with $100 \mathrm{mg} \mathrm{L}^{-1}$ of the insecticide were significantly shorter or similar than the ones observed in the respective controls in AM 1, GM 3 and GM 4 strains. An increase of $28 \%$ in this parameter was observed in the strain AM 2 with 500 and $600 \mathrm{mg} \mathrm{L}^{-1}$.

The analysis of variance of the effect of single $\left(\mathrm{a}_{\mathrm{W}}\right.$, insecticide concentration and strains) and two and three-way interaction showed that insecticide concentration, aw and all the possible interactions were statistically significant in relation to the growth rate. As regard lag phase, each single variable and their interactions were statistically significant $(\mathrm{p}<0.0001)$ (Table 2$)$.

Growth of Aspergillus section Flavi strains in the presence of commercial chlorpyrifos formulation as sole source of carbon, phosphorus or nitrogen

Figure 2 shows the growth rate of four Aspergillus section Flavi strains in control media and in presence of different chlorpyrifos concentrations as the sole carbon, phosphorous or nitrogen source. All the strains showed a similar growth pattern in all media analyzed. The highest values of growth rate were observed in the full $\mathrm{CZ}$ medium (7.2 to $8 \mathrm{~mm} \mathrm{day}^{-1}$ ) and the lowest values were registered in the medium where the insecticide replaced the carbon source (CZC) (3.6 to $\left.4.4 \mathrm{~mm} \mathrm{day}^{-1}\right) \quad(\mathrm{p}<0.001)$. Regarding the modified media, this parameter was significantly higher in $\mathrm{CZN}$ than in CZP in all strain tested. Although the values of growth rate observed in $\mathrm{CZN}$ and CZP media were significantly higher than in $\mathrm{CZC}$, they did not reach the values registered in $\mathrm{CZ}$ medium. The average reductions of growth rate observed in $\mathrm{CZN}$ and $\mathrm{CZP}$ media in comparison to $\mathrm{CZ}$ medium were 5 and $14 \%$ respectively. 
With regard to lag phase, in concordance with growth rate results, all the strains had a similar behavior. The longest lag phases were observed in CZC medium $(\mathrm{p}<0.001)$, followed by $\mathrm{CZN}$ and $\mathrm{CZP}$ media. When chlorpyrifos replaced the phosphorous source, no significant differences between this media and control (CZ) were observed, except in GM 3 and GM 4 strains. GM 4 strain showed the greatest differences in this parameter between the $\mathrm{CZ}$ and $\mathrm{CZP}$ media (29.7 and $18.8 \mathrm{~h}$, respectively). Regarding the other control treatment (WA), the lag phases in CZP media were significantly shorter than in WA media $(\mathrm{p}<0.001)$. On the contrary, no significant differences were observed between the lag phases registered in CZN and the ones registered in WA media, except in GM 4 strain (Table 3).

The analysis of variance of growth rates showed that each single variable analyzed (media and strains) and their interactions were statistically significant. On the contrary, media and their interaction with the strains were statistically significant with respect to lag phase (Table4).

\section{Chlorpyrifos degradation in synthetic medium}

Recovery of $93 \pm 7.4 \%$ was obtained from $\mathrm{CZ}$ medium at chlorpyrifos levels tested. Figure 3 shows the degradation of chlorpyrifos by two $A$. oryzae strains after 30 days of incubation at three $\mathrm{a}_{\mathrm{w}}$ conditions. Both A. oryzae strains showed similar behavior at all conditions tested. Chlorpyrifos degradation was detected from the first day of incubation and the degradation percentage was $75 \%$ at 0.98 and 0.95 of $\mathrm{a}_{\mathrm{w}}$, in all concentrations and strains tested. Meanwhile, at 0.93 of $\mathrm{aw}_{\mathrm{w}}$, this percentage was significantly lower in all concentrations and strains assayed $(<25 \%)$. In general, a fast decrease of chlorpyrifos in the medium was observed within the first day of incubation, and then the biodegradation rate decreased over time $(\mathrm{p}<0.001)$.

The analysis of variance on the effect of single variables, e.g. strains, aw and insecticide levels showed that all factors alone and all interactions were statistically significant $(\mathrm{p}<0.001)$ in relationship to chlorpyrifos degradation on synthetic medium.

Fungi have been successfully used to remove a great variety of xenobiotic compounds (Singh, 2008). Mycelia growth and extracellular enzymes provides them an advantage over others microorganisms like bacteria and yeasts. Several authors have reported microorganisms, both fungi and bacteria, with the potential ability to degrade chlorpyrifos (Maya et al., 2012; Chishti et al., 2013; Dhanya, 2014). There is scarce information about chlorpyrifos tolerance or degradation by fungal strains (Omar, 1998; Karas et al., 2011; Maya et al., 2012), even more by Aspergillus spp. strains (Silambarasan and Abraham, 2013; Hindumathy and Gayathri, 2013; Yavad et al., 2014; Carranza et al., 2014).

The results observed in the present work partially agree with those informed by Silambarasan and Abraham (2013). They observed that an Aspergillus terreus strain isolated from agricultural soil was able to tolerate chlorpyrifos concentrations up to $400 \mathrm{mg} \mathrm{L}^{-1}$ in a mineral synthetic medium. While the assayed concentrations in this study reached to $700 \mathrm{mg} \mathrm{L}^{-1}$ in AESO medium and we did not observed a decrease in fungal growth higher than the $50 \%$ in all strains and concentrations tested. In addition, these authors observed an increase in the dry weight of $A$. terreus in the medium with $300 \mathrm{mg} \mathrm{L}^{-1}$ of chlorpyrifos as 
carbon source. This result is comparable to the observed in the present work due to the highest values of growth rate were registered with chlorpyrifos concentration between 300 and $500 \mathrm{mg} \mathrm{L}^{-1}$. The differences in chlorpyrifos tolerance could be attributed to the media composition. The rich medium allowed a greatest tolerance of the insecticide.

In a previous work we evaluated the tolerance to three pesticides (among them chlorpyrifos) of Aspergillus section Nigristrains in soil-based medium (Carranza et al., 2014). Unlike the results observed in the present study, significant decreases in the growth rate of Aspergillus section Nigri strains with increasing chlorpyrifos concentrations $\left(5,10\right.$ and $\left.20 \mathrm{mg} \mathrm{L}^{-1}\right)$ were observed. As regard lag phase, in both studies significant increases in this parameter with increasing chlorpyrifos concentrations were registered.

The results of the replacement of the different nutrient sources by the insecticide showed that all strains tested were able to develop in a synthetic medium with the pesticide as the only carbon, phosphorous and nitrogen source. Recently we informed that these Aspergillus section Flavi strains showed the ability to develop with glyphosate as the sole source of carbon, phosphorous and nitrogen (Carranza et al., 2016b). With respect to growth rate, the results were comparable for both pesticides. The highest values of this parameter were observed when both pesticides replaced the nitrogen source. Nevertheless, when chlorpyrifos replaced the carbon source the lowest values of growth rate were registered; while with glyphosate this behavior was observed in WA medium, and between the media CZC and CZP the values registered were similar. Regarding the lag phase, the strains assayed need more than 29 hours to develop in a medium where the glyphosate replaced the carbon, phosphorous or nitrogen source; whereas that with chlorpyrifos this time was lower (18 hs). The duration of this growth parameter was lower in the medium where the glyphosate replaced the nitrogen source, while with chlorpyrifos this fact was observed in CZP medium. As regard $\mathrm{CZ}$ medium (control treatment), the lag phases in modified media (CZC, CZP and CZN) were longer than the respective control. However with chlopyrifos, the lag phases registered in CZP medium were similar to the ones observed in the control $(\mathrm{CZ})$. These results indicate that the presence of chlorpyrifos produce an induction of hydrolytic enzymes that could be involved in the insecticide degradation. The adaptation time in this media appears to depend on the way of the strains tested metabolize the insecticide.

In other study it was also evaluated the growth of Aspergillus strains in presence of chlorpyrifos (100 $\left.\mathrm{mg} \mathrm{L}^{-1}\right)$ and in presence/absence of glucose as carbon source (Hindumathy and Gayathri, 2013). These authors informed that the strains showed an increase in their protein content in the medium with chlorpyrifos and without glucose, supporting the ability of these strains to use the insecticide as carbon and energy source. These results are in agreement with those informed in the present work, since they are also reporting that chlorpyrifos can be used as the only carbon source.

Several studies inform about tolerance and degradation of chlopyrifos by different fungal species both on in vitro conditions and on soil, being this insecticide added as the carbon source in most of the works (Fang et al., 2008; Kulshrestha and Kumari 2011; Maya et al., 2012; Gao et al., 2012; Silambarasan and Abraham, 2013; 
Hindumathy and Gayathri, 2013; Yadav et al., 2015). However, there is little information about tolerance or degradation of this insecticide added as phosphorous or nitrogen source (Omar 1998). Fang et al.(2008) observed that a Verticillium sp. strain was able to develop and increase their biomass with chlorpyrifos as the only carbon source $\left(100 \mathrm{mg} \mathrm{L}^{-1}\right)$ after five days of incubation.

Maya et al., (2012) obtained similar results in terms of dry weight of different fungal strains with chlorpyrifos as the carbon source (in levels between 50 and $500 \mathrm{mg} \mathrm{L}^{-}$ $\left.{ }^{1}\right)$. In the same way, Silambarasan and Abraham (2013) also observed a significant increase in dry weight and growth rate of $A$. terreus in a mineral medium added with 300 $\mathrm{mg} \mathrm{L}^{-1}$ of chlorpyrifos as the only carbon source.

Regarding chlorpyrifos degradation, Briceño et al. (2012) informed that two Streptomyces sp. strains isolated from soil were able to degrade the insecticide at levels of $90 \%$ of degradation. A complete mineralization of $50 \mathrm{mg} \mathrm{L}^{-1}$ of chlorpyrifos after 5 days using a co-culture of bacteria and Trichosporum spp. was reported by $\mathrm{Xu}$ et al., (2007).

In other study, Kulshrestha and Kumari (2011) reported a high degradation $(83.9 \%)$ of chlorpyrifos by a strain of Acremonium sp. Also, Gaoet al. (2012) obtained similar results with Cladosporium cladosporioides strain. Karas et al.(2011) evaluated the degradation of several pesticides (among them chlorpyrifos) by three white rot fungi and one strain of $A$. niger.

All the strains assayed were able to degrade the insecticide $\left(20 \mathrm{mg} \mathrm{L}^{-1}\right)$ in a soil-based medium and in straw extract medium. A fast decrease of chlorpyrifos was registered within the first two days of incubation for all strains tested. All the results before mentioned are in agreement with the informed in the present study.

Omar (1998) observed that A. terreus had the greatest potential to mineralize organic phosphorous and sulfur from chlorpyrifos in liquid media followed by $A$. tamari and $A$. niger among other fungal species. At 10, 50 and $100 \mathrm{mg} \mathrm{L}^{-1}$ of chlorpyrifos, the degradation percentages were 16.7, 6.3 and $3.5 \%$, respectively when chlorpyrifos replaced the phosphorous source; and 56.3, 24.4 and $21.7 \%$ respectively when the sulfur source was replaced by the insecticide. In the present work, higher degradation percentages were registered on optimal growth conditions $(0.98,0.95$ of aw and $25^{\circ} \mathrm{C}$ ) and comparable results (about $25 \%$ of degradation) were observed at 0.93 of aw.

Maya et al. (2012) observed that Aspergillus strains had the ability to degrade faster both the insecticide (62.3 to 92.6\%) and TCP (69.4 to $89.9 \%$ ) at a concentration up to 200 $\mathrm{mg} \mathrm{L}^{-1}$. These results are comparable to the degradation percentages registered in the present study.

Recently, Yadav et al. (2015) evaluated aerobic biodegradation of chlorpyrifos by Aspergillus sp. in batch and continuous packed bed bioreactors. In general, degradation percentages around 90\% were observed at the optimized culture conditions (oxygen saturation: $5.8 \mathrm{mg} \mathrm{L}^{-1}$; inoculum level: $2.5 \mathrm{mg} \mathrm{mL}^{-1}$ wet weight; $\mathrm{pH}: 7$; temperature: $28^{\circ} \mathrm{C}$ ).

These percentages were registered at chlorpyrifos concentrations up to $300 \mathrm{mg} \mathrm{L}^{-}$ 1; thereafter it decreased rapidly. These results did not agree with the informed in the present study since we observed lower degradation percentages at optimal culture conditions. 
Table.1 Effect of different chlorpyrifos concentrations on the lag phase (h) of Aspergillus section Flavi strains in SEA medium under different water activity (aW) conditions at $25^{\circ} \mathrm{C}$.

\begin{tabular}{|c|c|c|c|c|c|c|c|c|c|}
\hline \multirow{3}{*}{ Strains } & \multirow{3}{*}{$\mathbf{a}_{W}$} & \multicolumn{8}{|c|}{ Lagphase (h) \pm SD } \\
\hline & & \multicolumn{8}{|c|}{ Chlorpyrifos $\left(\mathrm{mg} \mathrm{L}^{-1}\right)$} \\
\hline & & $\mathbf{0}$ & 100 & 200 & 300 & 400 & 500 & 600 & 700 \\
\hline AM1 & $\begin{array}{l}0.995 \\
0.980\end{array}$ & $\begin{array}{l}32.0 \pm 2.7 \mathrm{ij} \\
37.6 \pm 1.8 \mathrm{~g}\end{array}$ & $\begin{array}{l}33.1 \pm 2.6 \mathrm{ij} \\
35.0 \pm 2.8 \mathrm{hi}\end{array}$ & $\begin{array}{l}33.9 \pm 3.7 \mathrm{hi} \\
37.0 \pm 1.0 \mathrm{gh}\end{array}$ & $\begin{array}{c}42.6 \pm 2.6 \mathrm{ef} \\
43.4 \pm 1.4 \mathrm{e}\end{array}$ & $\begin{array}{c}43.7 \pm 0.6 \mathrm{de} \\
46.7 \pm 2.5 \mathrm{c}\end{array}$ & $\begin{array}{c}43.1 \pm 2.0 \mathrm{e} \\
46.3 \pm 3.0 \mathrm{~cd}\end{array}$ & $\begin{array}{l}44.8 \pm 1.5 \mathrm{~d} \\
44.8 \pm 1.2 \mathrm{~d}\end{array}$ & $\begin{array}{c}45.3 \pm 4.8 d \\
47.5 \pm 2.4 b c\end{array}$ \\
\hline AM2 & $\begin{array}{l}0.995 \\
0.980\end{array}$ & $\begin{array}{l}31.7 \pm 0.7 \mathrm{j} \\
33.8 \pm 1.5 \mathrm{i}\end{array}$ & $\begin{array}{l}32.4 \pm 2.0 \mathrm{ij} \\
37.9 \pm 0.7 \mathrm{~g}\end{array}$ & $\begin{array}{l}35.3 \pm 1.0 \mathrm{~h} \\
38.5 \pm 3.4 \mathrm{~g}\end{array}$ & $\begin{array}{l}33.5 \pm 1.6 \mathrm{i} \\
41.4 \pm 0.3 \mathrm{f}\end{array}$ & $\begin{array}{l}39.0 \pm 2.2 \mathrm{fg} \\
44.1 \pm 1.2 \mathrm{de}\end{array}$ & $\begin{array}{c}44.0 \pm 2.8 \mathrm{de} \\
43.4 \pm 0.3 \mathrm{e}\end{array}$ & $\begin{array}{l}41.9 \pm 0.4 \mathrm{f} \\
43.3 \pm 1.7 \mathrm{e}\end{array}$ & $\begin{array}{c}41.3 \pm 0.2 \mathrm{f} \\
45.9 \pm 0.7 \mathrm{~cd}\end{array}$ \\
\hline GM3 & $\begin{array}{l}0.995 \\
0.980\end{array}$ & $\begin{array}{l}30.0 \pm 0.7 \mathrm{j} \\
35.3 \pm 1.3 \mathrm{~h}\end{array}$ & $\begin{array}{l}33.7 \pm 1.9 \mathrm{i} \\
35.5 \pm 1.6 \mathrm{~h}\end{array}$ & $\begin{array}{l}39.1 \pm 0.3 \mathrm{fg} \\
42.6 \pm 1.2 \mathrm{ef}\end{array}$ & $\begin{array}{l}42.5 \pm 1.8 \mathrm{ef} \\
43.9 \pm 0.7 \mathrm{de}\end{array}$ & $\begin{array}{c}43.7 \pm 0.6 \mathrm{de} \\
43.0 \pm 0.7 \mathrm{e}\end{array}$ & $\begin{array}{l}42.9 \pm 0.4 \mathrm{e} \\
44.9 \pm 1.2 \mathrm{~d}\end{array}$ & $\begin{array}{c}50.4 \pm 1.3 \mathrm{ab} \\
43.1 \pm 3.9 \mathrm{e}\end{array}$ & $\begin{array}{c}53.4 \pm 2.4 a \\
45.7 \pm 0.4 c d\end{array}$ \\
\hline GM4 & $\begin{array}{l}0.995 \\
0.980\end{array}$ & $\begin{array}{l}35.1 \pm 1.2 \mathrm{hi} \\
37.8 \pm 2.0 \mathrm{~g}\end{array}$ & $\begin{array}{c}37.4 \pm 0.8 \mathrm{~g} \\
37.0 \pm 2.9 \mathrm{gh}\end{array}$ & $\begin{array}{c}35.9 \pm 2.0 \mathrm{~h} \\
40.4 \pm 1.1 \mathrm{fg}\end{array}$ & $\begin{array}{c}41.4 \pm 0.9 f \\
42.3 \pm 2.2 \mathrm{ef}\end{array}$ & $\begin{array}{l}48.8 \pm 4.0 \mathrm{~b} \\
45.2 \pm 1.9 \mathrm{~d}\end{array}$ & $\begin{array}{c}45.8 \pm 0.8 \mathrm{~cd} \\
44.8 \pm 1.2 \mathrm{~d}\end{array}$ & $\begin{array}{l}47.3 \pm 1.4 c \\
46.8 \pm 1.5 c\end{array}$ & $\begin{array}{l}44.0 \pm 3.5 \mathrm{de} \\
48.4 \pm 3.8 \mathrm{bc}\end{array}$ \\
\hline
\end{tabular}

AM 1, AM 2 and GM 3: Aspergillusoryzae strains, GM 4: Aspergillusflavus strain. The letters in common are not significantly different according to Fisher's protected least significant difference (LSD) test $(\mathrm{P}<0.0001)$.

SD: standard deviation. SEA: soybean extract agar.

Table.2 Analysis of variance of water availability (aW), effect of insecticide concentration (C), different strains (I) and their interactions on growth rate and lag phase on SEA medium.

\begin{tabular}{|c|c|c|c|c|c|}
\hline \multirow{2}{*}{$\begin{array}{l}\text { Source of } \\
\text { variation }\end{array}$} & \multirow[t]{2}{*}{$\mathbf{D f}^{\dagger}$} & \multicolumn{2}{|c|}{ Growth rate } & \multicolumn{2}{|c|}{ Lag phase } \\
\hline & & $\mathbf{M S}^{\dagger}$ & $\mathbf{F}^{\S}$ & $\mathbf{M S}^{\star}$ & $\mathbf{F}^{\S}$ \\
\hline I & 3 & 0.83 & 5.53 & 92.63 & $23.97 *$ \\
\hline $\mathrm{C}$ & 7 & 10.13 & $67.42 *$ & 548.01 & $141.80 *$ \\
\hline $\mathrm{a}_{\mathrm{W}}$ & 1 & 4.07 & $27.07 *$ & 136.87 & $35.42 *$ \\
\hline I x C & 21 & 0.61 & $4.03 *$ & 15.86 & $4.10 *$ \\
\hline $\mathrm{I} \times \mathrm{a}_{\mathrm{W}}$ & 3 & 2.02 & $18.25^{*}$ & 34.96 & $9.05 *$ \\
\hline $\mathrm{I} \times \mathrm{C} \times \mathrm{a}_{\mathrm{W}}$ & 21 & 0.62 & $4.11^{*}$ & 14.11 & $3.65^{*}$ \\
\hline $\begin{array}{l}\text { † Degrees of fr } \\
\text { † Mean square. } \\
\text { §F-Snedecor. } \\
\text { * Significant } \mathrm{P} \\
\text { SEA: soybea }\end{array}$ & 001 & & & & \\
\hline
\end{tabular}


Table.3 Lag phases of Aspergillus section Flavi strains in water agar and CzapekDox agar media supplied with chlorpyrifos as the sole source of carbon, phosphorus or nitrogen.

\begin{tabular}{cccccc}
\hline \multirow{2}{*}{ Strains } & \multicolumn{5}{c}{ Lagphase (h) \pm SD } \\
\cline { 2 - 6 } & WA & CZ & CZC & CZP & CZN \\
\hline AM 1 & $31.6 \pm 1.8 \mathrm{de}$ & $28.5 \pm 0.7 \mathrm{fg}$ & $39.4 \pm 2.7 \mathrm{a}$ & $27.6 \pm 0.6 \mathrm{gh}$ & $33.7 \pm 1.0 \mathrm{~cd}$ \\
AM 2 & $30.7 \pm 1.2 \mathrm{ef}$ & $25.1 \pm 1.4 \mathrm{~h}$ & $35.0 \pm 2.6 \mathrm{bc}$ & $25.3 \pm 1.1 \mathrm{~h}$ & $31.3 \pm 0.5 \mathrm{de}$ \\
GM 3 & $32.1 \pm 0.9 \mathrm{de}$ & $30.3 \pm 2.6 \mathrm{fg}$ & $33.7 \pm 0.9 \mathrm{~cd}$ & $25.7 \pm 1.5 \mathrm{~h}$ & $31.6 \pm 0.4 \mathrm{de}$ \\
GM 4 & $31.7 \pm 0.8 \mathrm{de}$ & $29.7 \pm 1.0 \mathrm{fg}$ & $36.0 \pm 1.1 \mathrm{bc}$ & $18.8 \pm 1.8 \mathrm{i}$ & $36.9 \pm 3.8 \mathrm{ab}$ \\
\hline
\end{tabular}

WA: water agar. CZ: CzapekDox medium. CZC: CzapekDox medium without sucrose and supplied with chlorpyrifos at $50 \mathrm{mg} \mathrm{L}^{-1}$, CZP: CzapekDox medium without $\mathrm{K}_{2} \mathrm{HPO}_{4}$ and supplied with glyphosate at $10 \mathrm{mg} \mathrm{L}^{-1}$, CZN: CzapekDox medium without $\mathrm{NaNO}_{3}$ and supplied with glyphosate at $10 \mathrm{mg} \mathrm{L}{ }^{-1}$.

Values represent the mean of four replicates. SD: standard deviation. Means from each species with the same letter are not significantly different according to the LSD test $(\mathrm{p}<0.001)$.

Table.4 Variance analysis of effect of media (M), strains (I) and their interactions on lag phase and growth rate of Aspergillus section Flavi strains in Czapek Dox agar medium supplied with chlorpyrifos as the sole source of carbon, phosphorus or nitrogen.

\begin{tabular}{|c|c|c|c|c|c|}
\hline \multirow{2}{*}{$\begin{array}{l}\text { Source of } \\
\text { variation }\end{array}$} & \multirow[t]{2}{*}{$D^{\dagger} f^{\dagger}$} & \multicolumn{2}{|c|}{ Growth rate } & \multicolumn{2}{|c|}{ Lag phase } \\
\hline & & $\mathbf{M S}^{\dagger}$ & $\mathbf{F}^{\S}$ & $\mathbf{M S}^{\ddagger}$ & $\mathbf{F}^{\S}$ \\
\hline $\mathrm{M}$ & 4 & 27.38 & $1570.27 *$ & 246.66 & $88.13 *$ \\
\hline I & 3 & 2.21 & $126.55^{*}$ & 17.80 & 6.36 \\
\hline M x I & 12 & 0.12 & $6.66 *$ & 20.28 & $7.25 *$ \\
\hline $\begin{array}{l}\text { Degrees of fr } \\
{ }^{*} \text { Mean square. } \\
{ }^{5} \text { F-Snedecor. } \\
* \text { Significant }\end{array}$ & & & & & \\
\hline
\end{tabular}


Fig.1 Growth rate of Aspergillus oryzae: AM 1, AM 1 and GM3 strains; and Aspergillus flavus GM 4 strain on soybean extract agar at $0.995($ ) and $0.980($ ) of aW. Mean values based on triplicated data. Mean with a letter in common are not significantly different according to LSD test ( $\mathrm{p}>0.0001)$.
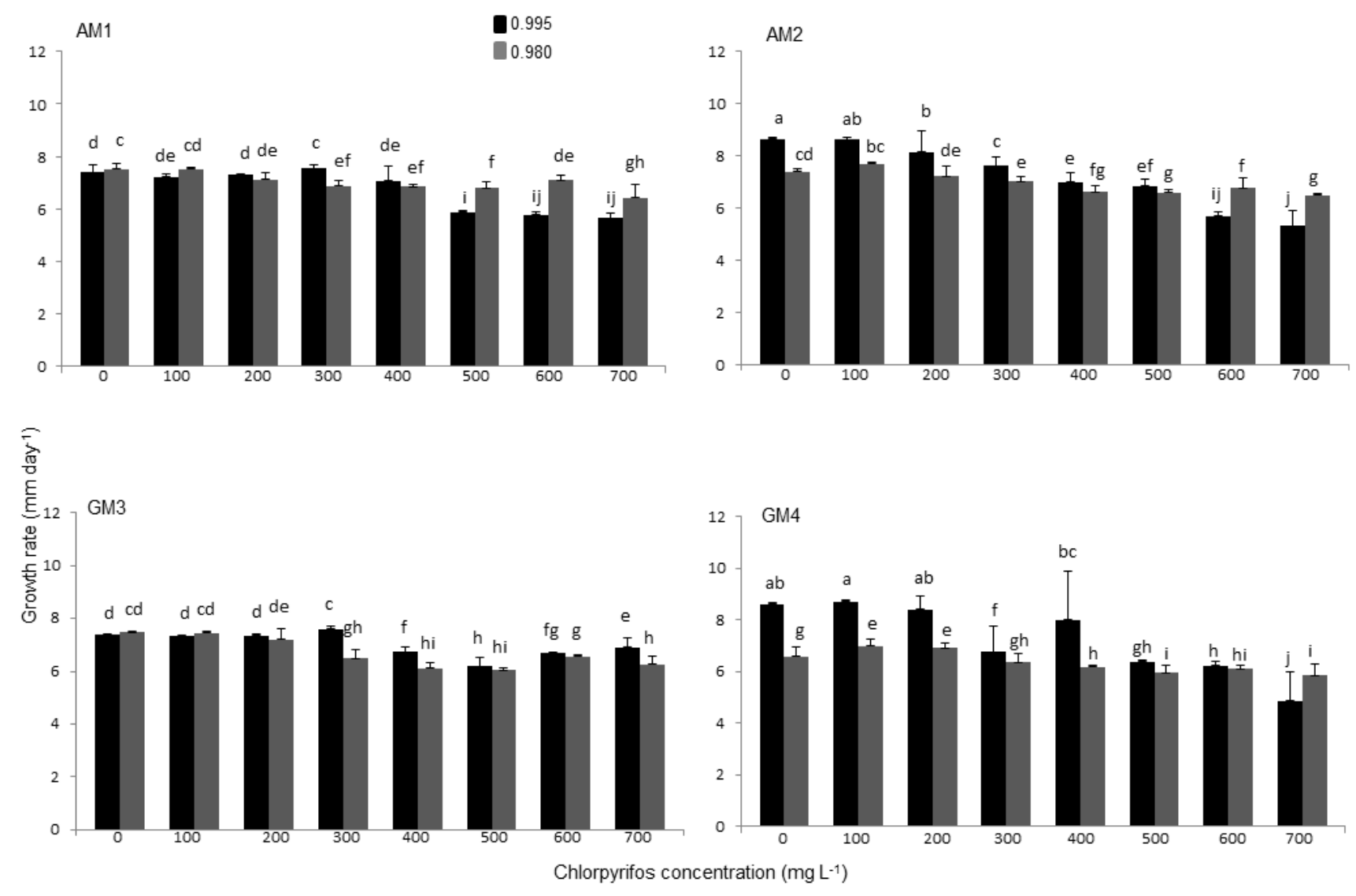
Fig.2 Growth rate of Aspergillus section Flavi strains on water agar WA ( ), CzapekDox medium CZ ( ), CzapekDox medium without sucrose and supplied with chlorpyrifos as the sole carbon source CZC ( ), CzapekDox medium without K2HPO4 or NaNO3and supplied with chlorpyrifos as the only phosphorous CZP ( ) or nitrogen source CZN ( ).Mean values based on triplicated data. Mean with a letter in common are not significantly different according to LSD test (p $\square 0.001)$.

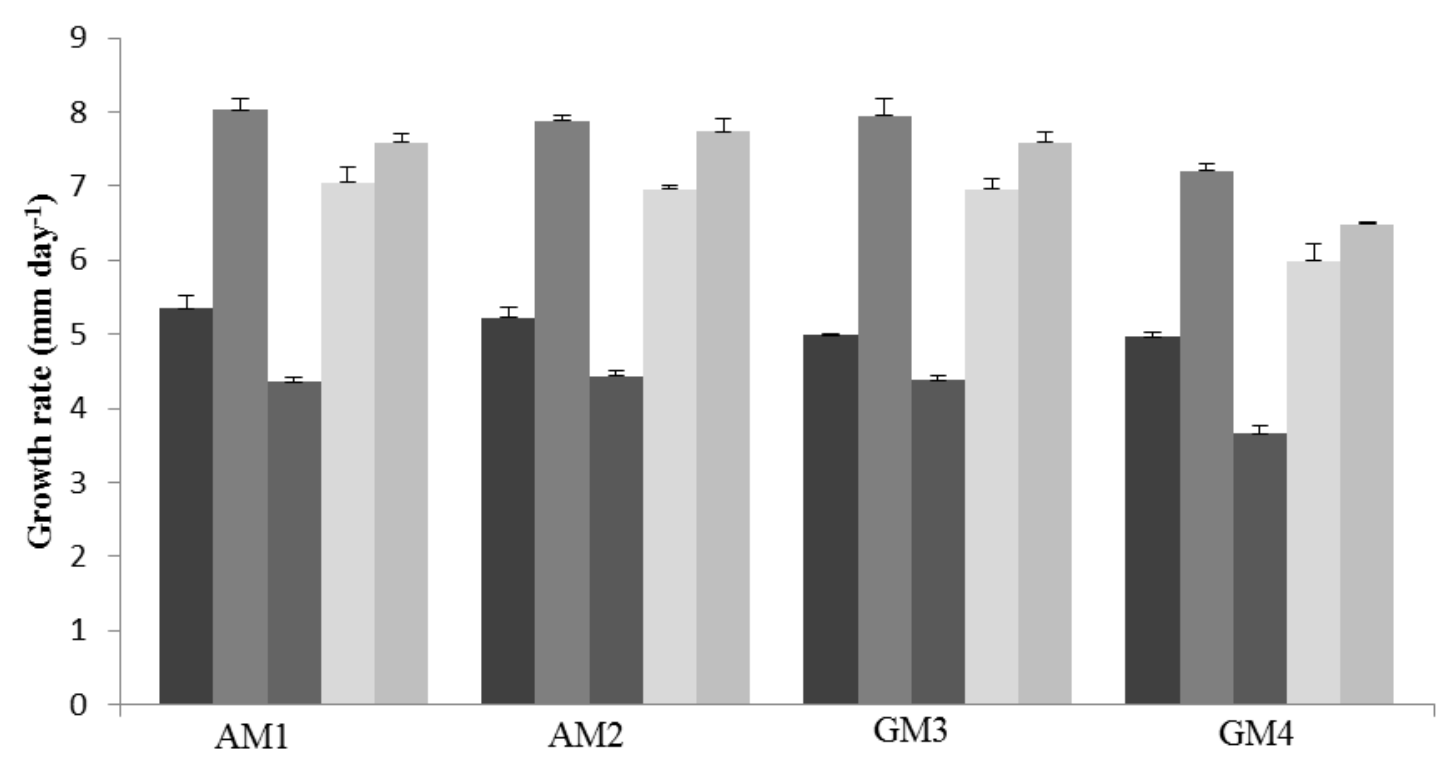


Fig.3 Chlorpyrifos degradation on broth Czapeck medium (CZ) adjusted to 0.980, 0.950 and 0.930 of aW by A. oryzae AM 1 (A) and AM 2 (B) strains. Mean values based on triplicated data. Mean with a letter in common are not significantly different according to LSD test ( $p>0.001)$.
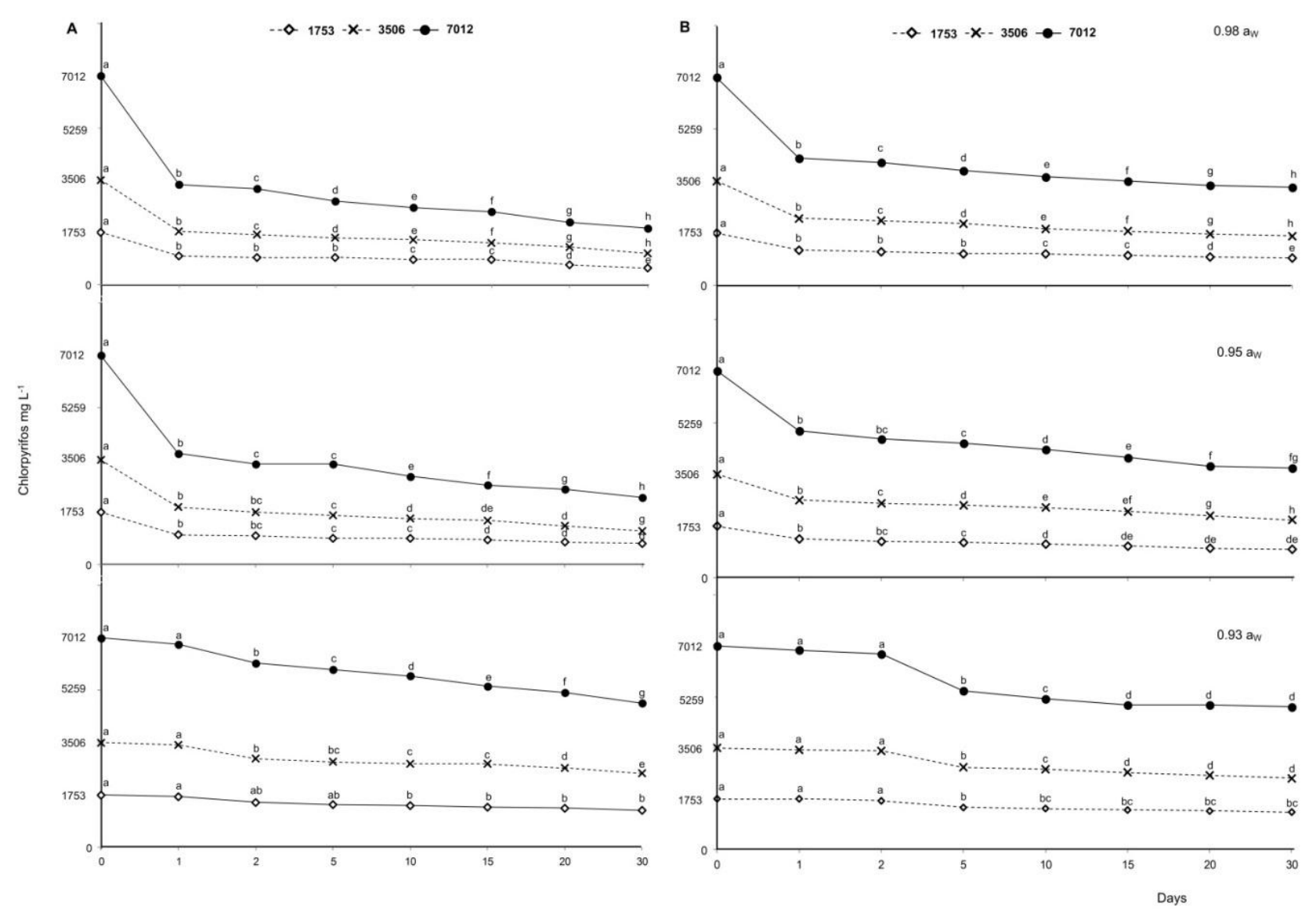
Hindumathy and Gayathri (2013) studied chlorpyrifos degradation $\left(100 \mathrm{mg} \mathrm{L}^{-1}\right)$ in a mineral synthetic medium by both bacteria and fungi (Aspergillus species) with or without the addition of glucose. These authors observed that both bacterial and fungal strains were able to degrade the insecticide at high percentages alone (73.3 and $58 \%$ respectively) and with the addition of the carbon source (84 and $76 \%$ respectively). These results partially agree with the registered in the present study. A $75 \%$ of degradation at 0.98 and 0.95 of aw in all concentrations and strains tested was observed. These water availability conditions and $25^{\circ} \mathrm{C}$ are the optimal conditions for the growth of the strains tested. Meanwhile, at 0.93 of $\mathrm{a}_{\mathrm{w}}$ (a stress condition) and optimal temperature, this percentage was reduced significantly $(<25 \%)$ in all concentrations and strains assayed. It is important to mention that in the present work we observed that the water availability, at optimal temperature, affect the degradation of the insecticide. This variable was not considered in the other studies.

These non-toxigenic Aspergillus section Flavi isolated from agricultural soils have the ability to tolerate high levels of chlorpyrifos (70 times higher than the dose used at field fumigation). They can use the insecticide mainly as phosphorous and nitrogen source, and to a lesser extent as carbon source. The degradation studies showed that the $A$. oryzae strain has good chlorpyrifos degradation ability under optimal environmental conditions $\left(\mathrm{a}_{\mathrm{W}}\right.$ and temperature) for growth. As cleavage of chlorpyrifos depend on the microorganisms and environmental conditions, these studies indicate the need to detect the degradation products and to perform in situ degradation tests (microcosm conditions and soil).

\section{Acknowledgements}

This work was supported by Agencia Nacional de Promoción Científica y Tecnológica (ANPCYT-PICT- 2482/10) and Secretaría de Ciencia y Técnica, Universidad Nacional de Río Cuarto (SECYT-UNRC- 18/C391). C.S. Carranza and M.E. Aluffi are fellows from Consejo Nacional de Investigaciones Científicas y Técnicas (CONICET), C.L. Barberis, and C.E. Magnoli are members of the research career from CONICET.

\section{References}

Abo-Amer, A.E. 2011. Biodegradation of diazinon by Serratia marcescens DI101 and its use in bioremediation of contaminated environment. $J$. Microbiol. Biotechnol., 21: 71-80.

Agrobit. 2013. Control de malezas en soja. (http://www.agrobit.com.ar./Info_tecnic a/agricultura/soja).Accessed: June 2015. Alvarez, M., Mortier, C., Fernández Cirelli, A. 2013. Behavior of insecticide chlorpyrifos on soils and sediments with different organic matter content from provincia de Buenos Aires, República Argentina. Water, Air and Soil Poll., 224: 1453.

Antunes, S., Pereira, J., Cachada, A., Duarte, A., Gonçalves, F., Sousa, J., Pereira, R. 2010. Structural effects of the bioavailable fraction of pesticides in soil: suitability of elutriate testing. $J$. Hazardous Materials, 184: 215-225.

Awad, N.S., Sabit, H.H., Abo-Aba, S.E.M., and Bayoumi, R.A. 2011. Isolation, characterization and finger printing of some chlorpyrifos-degrading bacterial strains isolated from Egyptian pesticides-polluted soils. African $J$. Microbiol. Res., 5: 2855-2862.

Barberis, C., Astoreca, A., Fernandez-Juri, M.G., Dalcero, A.M., Magnoli, C.E. 
2010. Effect of antioxidant mixtures on growth and ochratoxin A production of Aspergillus section Nigri species under different water activity conditions on peanut meal extract agar. Toxins, 2: 1399-1413.

Barberis, C., Dalcero, A.M., Magnoli, C.E. 2012. Evaluation of aflatoxin $B_{1}$ and ochratoxin $\mathrm{A}$ in interacting mixed cultures of Aspergillus sections Flavi and Nigri on peanut grains. Mycotoxin Res., 28: 149-156.

Bhagobaty, R.K., Malik, A. 2008. Utilization of chlorpyrifos as a sole source of carbon by bacteria isolated from wastewater irrigated agricultural soils in an industrial area of western Uttar Pradesh, India. Res. J. Microbiol., 3: 293-307.

Bootharaju, M.S., Pradeep, T. 2012. Understanding the degradation pathway of the pesticide, chlorpyrifos by noble metal nanoparticles. Langmuir, 28: 2671-2679.

Briceño, G., Fuentes, M.S., Palma, G., Jorquera, M.A., Amoroso, M.J., Diez, M.C. 2012. Chlorpyrifos biodegradation and 3,5,6-trichloro-2-pyridinol production by actinobacteria isolated from soil. Int. Biodeterioration and Biodegradation, 73: 1-7.

Brunstein, L., Digón, A., Licastro, S., Moreno, I. 2009. Generalidades sobre plaguicidas y control de plagas. In: Plaguicidas. Información y estrategias para la gestión ecológicamente racional de plaguicidas de uso sanitario. Departamento de Salud Ambiental. Dirección Nacional de Determinantes de la Salud e Investigación. Ministerio de Salud de la Nación. Buenos Aires, Argentina. pp 11 . (http://www.sertox.com.ar/img/itemfull/ LIBRO20IIfinal20febrero10.pdf.) Accessed: May 2013.

CASAFE. Cámara Argentina de Sanidad
Agropecuaria y Fertilizantes. 2014. Argentina market of plant protection products 2011-2012. Buenos Aires, Argentina.

(http://www.casafe.org/biblioteca/ estadisticas/). Accessed: August 2014.

Carranza, C.S., Bergesio, M.V., Barberis, C.L., Chiacchiera, S.M., Magnoli, C.E. 2014. Survey of Aspergillus section Flavi presence in agricultural soils and effect of glyphosate on nontoxigenic $A$. flavus growth on soil-based medium. $J$. Appl. Microbiol., 116: 1229-1240

Carranza, C.S., Barberis, C.L., Chiacchiera, S.M., Dalcero, A.M., Magnoli C.E. 2016a. Isolation of culturable mycobiota from agricultural soils and determination of tolerance to glyphosate of nontoxigenic Aspergillus section Flavi strains. J. Environ. Sci. Health, Part B, 51: 35-43.

Carranza, C.S., Barberis,C.L., Chiacchiera, S.M., and Magnoli, C.E. 2016b. Growth of Aspergillus flavus and Aspergillus niger aggregate strains isolated from agricultural soils in presence of glyphosate as sole source of carbon, phosphorous or nitrogen. Revista Argentina de Microbiología(in press).

Chishti, Z., Hussain, S., Arshad, K.R., Khalid, A., Arshad, M. 2013. Microbial degradation of chlorpyrifos in liquid media and soil. J. Environ. Management, 114: 372-380.

Chu, X.Q., Fang, H., Pan, X.D., Wang, X., Shan, M., Feng, B., and Yu, Y.L. 2008. Degradation of chlorpyrifos alone and in combination with chlorothalonil and their effects on soil microbial populations. J. Environ. Sci., 20: 464469.

Dallyn, H., Fox, A. 1980. Spoilage of material of reduced water activity by xerophilic fungi. In:Gould, G.H., Corry, J.E.L., Editors. Microbial growth and survival in extreme environments. 
London, New York: Academic Press: 129-139.

Dhanya, M.S. 2014. Advances in microbial biodegradation of chlorpyrifos. $J$. Environ. Res. Development, 9: 232-240.

Diez, M.C. 2010. Biological aspects involved in the degradation of organic pollutants. J. Soil Sci. Plant Nutri., 10: 244-267.

Domagalski, J.L., Munday, C. 2003. Evaluation of diazinon and chlorpyrifos concentrations and loads, and other pesticide concentrations, at selected sites in the San Joaquin Valley, California, April to August, 2001. Water-Resources Investigations Report 03-4088. Sacramento, California: United States Geologic Survey.

EPA. Environmental Protection Agency. 2000. Reregistration eligibility science chapter for chlorpyrifos fate and environmental risk assessment chapter, Washington, DC.

Fang, H., Xiang, Y.Q., Hao, Y.J., Chu, X.Q., Pan, X.D., Yu, J.Q., Yu, Y.L. 2008. Fungal degradation of chlorpyrifos by Verticillium sp. DSP in pure cultures and its use in bioremediation of contaminated soil and pakchoi. Int. Biodeterioration and Biodegradation, 61: 294-303.

Gao, Y., Chen, S., Hu, M., Hu, Q., Luo, J., Li, Y. 2012. Purification and characterization of a novel chlorpyrifos hydrolase from Cladosporium cladosporioides Hu-01. Plos One, 7: 6, e38137.

Gebremariam, S.Y., Beutel, M.W., Yonge, D.R., Flury, M., and Harsh, J.B. 2012. Adsorption and desorption of chlorpyrifos to soils and sediments. Rev. Environ. Contamination and Toxicol., 215: 123-175.

Ghanem, I., Orfi, M., and Shamma, M. 2007. Biodegradation of chlorpyrifos by Klebsiellasp. isolated from an activated sludge sample of waste water treatment plant in Damascus. Folia Microbiologica, 52: 423-427.

Gilliom, R.J., Barbash, J.E., Crawford, Ch.G., Hamilton P.A., Martin J.D., Nakagaki, N., Nowell, L.H., Scott, J. C., Stackelberg, P.E., Thelin, G.P., and Wolock, D.M. 2000. The Quality of Our Nation's Waters- Pesticides in the Nation's Streams and Ground Water, 1992-2000. U.S. Geological Survey Circular 1291, 172 p.

Hindumathy, C.K., Gayathri, V. 2013. Effect of pesticide (chlorpyrifos) on soil microbial flora and pesticide degradation by strains isolated from contaminated soil. Bioremediation and Biodegradation, 4: 178.

Karas, P.A., Perruchon, C., Exarhou, K., Ehaliotis, C., Karpouzas, D.G. 2011. Potential for bioremediation of agroindustrial effluents with high loads of pesticides by selected fungi. Biodegradation, 22: 215-228.

Kulshrestha, G., Kumari, A. 2011. Fungal degradation of chlorpyrifos by Acremonium sp. strain (GFRC-1) isolated from a laboratory enriched red agricultural. Biol. Fertility of Soils, 47: 219-225.

Latifi, A.M., Khodi, S., Mirzaei, M., Miresmaeili, M., Babavalian, H. 2012. Isolation and characterization of five chlorpyrifos degrading bacteria. African J. Biotechnol., 11: 3140-3146.

Liu, Z., Chen, X., Shi, Y., Su, Z. 2012. Bacterial degradation of chlorpyrifos by Bacillus cereus. Adv. Materials Res., 356-360: 676-680.

Loewy, R.M., Monza, L.B., Kirs, V.E., Savini, M.C. 2011. Pesticide distribution in an agricultural environment in Argentina. J. Environ. Sci. Health, Part B, 46: 662-670.

Massiha, A., Majid, M.R., Pahlaviani, K., Issazadeh, K. 2011. Microbial 
degradation of pesticides in surface soil using native strain in Iran. In: International Conference on Biotechnology and Environmental Management vol. 18. IPCBEE. IACSIT Press, Singapore, pp. 76-81.

Maya, K., Upadhyay, S.N., Singh, R.S., Dubey, S.K. 2012. Degradation kinetics of chlorpyrifos and 3,5,6-trichloro-2pyridinol (TCP) by fungal communities. Biores. Technol., 126: 216-223.

Muzio, J., Hilbert, J.A., Donato, L., Arena, P., Allende, D. 2008. Technical comments data biodiesel from soybeans directorate general for energy and transport. Instituto Nacional de Tecnología Agropecuaria (INTA), document number IIR-BC-INF-14-08.

Omar, S.A. 1998. Availability of phosphorus and sulfur of insecticide origin by fungi. Biodegradation, 9: 327336.and Vasil'chenko, L.G. 2004. Fungal decomposition of natural aromatic structures and xenobiotics. Appl. Biochem. Microbiol., 40: 1-17.

Rokade, K.B., Mali, G.V. 2013. Biodegradation of chlorpyrifos by Pseudomonas desmolyticumncim 2112. Int. J. Pharma and Bio Sci., 4: 609-616.

Sasikala, C., Jiwal, S., Rout, P., Ramya, M. 2012. Biodegradation of chlorpyrifos by bacterial consortium isolated from agriculture soil. World J. Microbiol. Biotechnol., 28: 1301-1308.

Savitha, K., Raman, D.N.S. 2012. Isolation, identification, resistance profile and growth kinetics of chlorpyrifos resistant bacteria from agricultural soil of Bangalore. Res. Biotechnol., 3: 8-13.

Silambarasan, S., Abraham, J. 2013. Ecofriendly method for bioremediation of chlorpyrifos from agricultural soil by novel fungus AspergillusterreusJAS1. Water, Air, and Soil Pollution, 224: 1369.

Singh, D.K. 2008. Biodegradation and bioremediation of pesticide in soil: concept, method and recent developments. Indian J. Microbiol., 48: 35-40.

Villamil Lepori, E.C., BoviMitre, G., Nassetta, M. 2013. Situación actual de la contaminación por plaguicidas en Argentina. Revista Internacional de ContaminaciónAmbiental, 29: 25-43.

Xu, G.M, Li, Y.Y., Zheng, W., Peng, X, Li, W., Yan, Y.C. 2007. Mineralization of chlorpyrifos by co-culture of Serratia and Trichosporonsp Biotechnol. Lett., 29: 1469-1473.

Yadav, M., Srivastva, N., Shukla, A.K., Singh, R.S., Upadhyay, S.N., Dubey, S.K. 2015. Efficacy of Aspergillus sp. for degradation of chlorpyrifos in batch and continuous aerated packed bed bioreactors. Appl. Biochem. Biotechnol., 175: 16-24.

Yu, Y.L., Fang, H., Wang, X., Wu, X.M., Shan, M., Yu, J.Q. 2006. Characterization of a fungal strain capable of degrading chlorpyrifos and its use in detoxification of the insecticide on vegetables. Biodegradation, 17: 487-494.

\section{How to cite this article:}

Cecilia Soledad Carranza, Melisa Eglé Aluffi, Carla LorenaBarberis and Carina Elizabeth Magnoli. 2016. Evaluation of Chlorpyrifos Tolerance and Degradation by Non-Toxigenic Aspergillus Section Flavi Strains Isolated from Agricultural Soils. Int.J.Curr.Microbiol.App.Sci. 5(7): 1-18. doi: http://dx.doi.org/10.20546/ijcmas.2016.507.001 